\title{
In This Issue: Mini-Theme on Geriatric Care and Cancer Screening
}

This issue includes several articles pertinent to geriatric medicine, ${ }^{1-6}$ along with a related commentary by Warshaw. ${ }^{7}$ In a striking pair of articles, Hudson ${ }^{4}$ provides evidence suggesting that prostate-specific antigen (PSA) testing is dramatically overused, whereas Mohan ${ }^{6}$ reports that men overestimate the value of treating prostate cancer diagnosed by PSA screening; both of these conditions lead to overtreatment. Although the US Preventive Services Task Force (USPSTF) ${ }^{8}$ does not recommend regular prostate cancer screening with PSA testing at any age group, even those professional groups that do recommend testing do not suggest doing so in men of advanced age. However, physicians and their patients are not following any of these guidelines when it comes to PSA testing, as reported by Hudson et al. ${ }^{4}$

The motivation to order an easy test for a common cancer seems great, and malpractice claims magnify the physician desire to do so. And, although specific informed consent can make a difference, it seems much easier to just do a simple blood test and avoid the time-intensive detailed informed consent required for the PSA test which has poor test characteristics. Apparently PSA testing is thought of as better than nothing by many men and their doctors. In turn, this overtesting translates into overtreatment.

Mohan et $\mathrm{al}^{6}$ clearly show that men overestimate the gain of treating prostate cancer found by PSA testing in terms of life expectancy. What to do? One answer is suggested in the Hudson study, ${ }^{4}$ which found that the practices with the best communication did better at not testing. Does this mean these practices have discussions with patients about when and how to test? Or, that office staff did not automatically assume PSA testing was needed? The answers to these questions could help us find an intervention to decrease overtesting. And, we need to work further on the role of the family physician in helping patients decide about prostate cancer

Conflict of interest: The authors are editors of the $7 A B F M$. treatment as well. It would also help if some major national group actually campaigned against PSA testing for men over age 75 .

Age itself, however, is not a major marker for complication in many diseases; this is explicitly found in Grover et al's ${ }^{2}$ study of urinary tract infections (UTIs), and this is also noted in the review of foot and ankle surgery for the older patient. ${ }^{5}$ In the UTI study, medical comorbidity was more important than age as a patient outcome factor. Similarly, as foot surgeries now involve less invasive procedures, medical comorbities are more important than age per se in determining who should receive these procedures or what the complication rates might be.

Daly et $\mathrm{al}^{1}$ give us new information important to adherence in patients with diabetes: the cost of self-behaviors and depression most interfered with diabetes control, whereas the hassle of self-behaviors were less of an issue. Diabetes is a disease that requires multiple types of self-behaviors, from eating well (which takes time, money, and planning) to exercise (again, at minimum takes time and planning) to medication (cost and planning) and doctor visits. Although we do not yet know whether depression decreases adherence and increases HbA1c or the opposite (ie, that poor diabetes control somehow creates depression on a physiologic level), certainly depression interferes with self-motivation and self-care. Given cost as a significant issue, insurers should consider making available low or no-cost medication ${ }^{9}$ and exercise opportunities, or they should financially reward those who do exercise regularly. Some insurers have successfully done so. ${ }^{10}$

Breast cancer risk assessment is diffusing into primary care practice. ${ }^{11}$ Women frequently ask about cancer risk, and physicians often provide answers. Many physicians have recommended testing for the breast cancer gene (BRCA1 and 2). A minority of physicians have used risk assessment software. For many patient questions, specific risk assessment instruments are not needed, given that not many women are particularly high risk and that 
many of the answers would be straightforward. However, when faced with a borderline or questionable case, the risk assessment software could clarify the need for testing.

Pain as a fifth vital sign collected by nurses was often done in a relatively informal manner, leading to some discrepancies with the standardized research measures as reported by Lorenz et al. ${ }^{12}$ Overall, the pain scale does not seem particularly helpful as a routine previsit measure: for example, do we mean pain at the moment, on average over this week, on average since last visit, or the most intense pain since last visit? Which pain-their knee pain, their neck pain, their tooth pain? Pain scales are more likely to be beneficial when used for addressing a specific individual problem, and they are likely to perform better for acute than chronic, intermittent pain.

In another common entity, atrial fibrillation, Niska et $\mathrm{al}^{13}$ note that an increasing percent of patients are receiving the recommended drug to prevent strokes-more than $50 \%$ of visits noted Coumadin/warfarin. Coumadin was less likely when aspirin was mentioned, and aspirin was being used for many patients instead of Coumadin. Although there are sometimes contraindications to warfarin, or strong patient preferences, the reasons for the choice of aspirin over Coumadin remain unclear, or undocumented. Meantime, there was also less prescribing of Coumadin for women or minorities, suggesting unwarranted disparities. We should think clearly and not make presumptions about adherence when considering Coumadin treatment for atrial fibrillation.

Howard et $\mathrm{al}^{3}$ find that consistency of care is associated with better blood pressure control, but, unfortunately, that African-Americans were less likely to receive consistent care. The reasons for these disparities are frequently related to the social determinants of health, from economics to racism. In fact, Gottlieb ${ }^{14}$ reminds us that the increasingly popular medical home concept will not trump the social determinants of health and questions what the role of the medical home should be in changing those same determinants. Food for thought. What are your thoughts on family medicine's role in changing the societal issues that prominently determine health?

Hand dermatitis ${ }^{15}$ is, in my (MAB) experience, less common in the elderly, because so much is related one way or another to people's work expo- sures, both irritant and allergic versions. Retirement sometimes works wonders in hand dermatitis that has evaded diagnosis for years.

Ueng et $\mathrm{al}^{16}$ present an interesting case of Long QT Syndrome masquerading as generalized epilepsy; this should be a reminder than Long QT Syndrome sometimes presents as seizures. The resting electrocardiogram may not reveal a long QT interval. Read this case to get a better handle on the distinguishing characteristics of Long QT Syndrome that can provide hints leading to its diagnosis.

We have a couple of other shorter pieces for consideration. Justin ${ }^{17}$ ruminates on being taken care of emotionally by former patients after retirement. In our research letter this month, White et $\mathrm{al}^{18}$ note the same high use of complementary and alternative medicine up to 9 years after immigration versus those who have been in the US more than 9 years.

Marjorie A. Bowman, MD, MPA Anne Victoria Neale, PhD, MPH

\section{References}

1. Daly JM, Hartz AJ, Xu Y, et al. An assessment of attitudes, behaviors, and outcomes of patients with type 2 diabetes. J Am Board Fam Med 2009;22(3): 280-90.

2. Grover ML, Bracamonte JD, Kanodia AK, Edwards FD, Weaver AL. Urinary tract infection in women over the age of 65: is age alone a marker of complication? J Am Board Fam Med 2009;22(3):266-71.

3. Howard DL, Carson AP, Holmes DN, Kaufman JS. Consistency of care and blood pressure control among elderly African Americans and whites with hypertension. J Am Board Fam Med 2009;22(3):30715.

4. Hudson SV, Ohman-Strickland P, Ferrante JM, LuYao G, Orzano AJ, Crabtree BF. Prostate-specific antigen testing among the elderly in communitybased family medicine practices. J Am Board Fam Med 2009;22(3):257-65.

5. Lee DK, Mulder GD. Foot and ankle surgery: considerations for the geriatric patient. J Am Board Fam Med 2009;22(3):316-24.

6. Mohan R, Beydoun H, Barnes-Ely ML, et al. Patients' survival expectations before localized prostate cancer treatment by treatment status. J Am Board Fam Med 2009;22(3):247-56.

7. Warshaw G. Providing quality primary care to older adults. J Am Board Fam Med 2009;22(3):239-41.

8. U.S. Preventive Services Task Force (USPSTF). Agency for Healthcare Research and Quality Web- 
site. Available from: http://www.ahrq.gov/clinic/ uspstfix.htm. Accessed 16 March 2009.

9. Strum MW, Hopkins R, West DS, Harris BN. Effects of a medication assistance program on health outcomes in patients with type 2 diabetes mellitus. Am J Health Syst Pharm 2005;62(10):1048-52.

10. Freudenheim $M$. To save later, some employers are offering free drugs. New York Times. 2007 February 21;A1.

11. Guerra CE, Sherman M, Armstrong K. Diffusion of breast cancer risk assessment in primary care. J Am Board Fam Med 2009;22(3):272-9.

12. Lorenz KA, Sherbourne CD, Shugarman LR, et al. How reliable is pain as the fifth vital sign? J Am Board Fam Med 2009;22(3):291-8.

13. Niska R, Han B. Anticoagulation for patients with atrial fibrillation in ambulatory care settings. J Am Board Fam Med 2009;22(3):299-306.
14. Gottlieb LM. Learning from Alma Ata: the medical home and comprehensive primary health care. J Am Board Fam Med 2009;22(3):242-6.

15. Perry AD, Trafeli JP. Hand dermatitis: review of etiology, diagnosis and treatment. J Am Board Fam Med 2009;22(3):325-30.

16. Chuang WY, Chuang YT, Ueng KC. Fourteen-year follow-up in a teenager with congenital long QT syndrome masquerading as idiopathic generalized epilepsy. J Am Board Fam Med 2009;22(3):331-4.

17. Justin RG. Serendipity. J Am Board Fam Med 2009; 22(3):335-6.

18. White B, Knox L, Zepeda M, Mull D, Nunez F. Impact of immigration on complementary and alternative medicine use in Hispanic patients. J Am Board Fam Med 2009;22(3):337-8. 